\title{
Comparison of ASTER, contour lines and LiDAR based DEMs in terms of topographic differences in forested area
}

\author{
Hüseyin Yurtseven \\ Department of Surveying and Cadastre, Faculty of Forestry, Istanbul University - Cerrahpasa, 34473 Istanbul, \\ Turkey \\ Corresponding author: huseyiny@istanbul.edu.tr
}

\begin{abstract}
DEMs (Digital Elevation Model) generated with different remote sensing techniques and technologies. DEMs are used to determine the changes of vegetation in forests depending on topographical factors. The accuracy of DEMs has a major impact on the planning and management of forests.

In this study, the accuracy of two different DEM data sources, which are frequently used in the modeling of topographic changes in large field studies in forestry, was compared with the LiDAR-based DEM dataset on a forest site. In this context, three different DEM source were used. One of them was the $10 \mathrm{~m}$ interval contour lines of 1:25,000 scale aerial photogrammetry based standard topographical maps which are produced by National General Directorate of Mapping. Topomap contour lines are transformed to grid based DEMs by using TIN and ANUDEM based approaches at 2.5, 5, 10 and 30 m resolutions. The other data was ASTER GDEM (1 arc-second ASTER GDEM Version 2, approximately $30 \mathrm{~m}$ resolution). The final and reference data is the LiDAR based, 0.25 m resolution DEM. In total, 33 DEM datasets are compared with the LiDAR-based DEM dataset. For these data sets, five difference metrics were calculated: pixel based difference models, the areal and volumetric difference of surface models, the areal difference of slope classes and the areal difference of aspect classes. According to the results of the analysis, the resolution, according to the topographic characteristics of the area and selected interpolation approaches has an effect on DEM modeling and DEM -derived metrics. In addition, the forest structure has a major impact on the accuracy of ASTER GDEM data.
\end{abstract}

Keywords: DEM, Accuracy, ASTER, Contour line.

\section{Introduction}

A digital elevation model (DEM) is a digital representation of the three-dimensional information of the Earth's surface. DEM is generally represented in the digital environment as a raster grid model or a triangular irregular network (TIN) model (Wilson and Gallant, 2000; Li et al., 2005; Li et al., 2017).

Digital elevation model (DEM) is the basis of computer-based topographic modeling and is one of the most important data for terrain-related applications. DEMs are widely applied in the fields of forestry (Aryal et al., 2017; Goodbody et al., 2018), agriculture (Tarolli et al., 2019), hydrology (Beven and Kirkby, 1979; Tarboton, 2003), soil (Blöschl and Sivapalan, 1995; Behrens et al., 2010; Florinsky, 2016; Behrens et al., 2018), landform (Flores-Prieto et al., 2015), military (Talhofer et al., 2015), etc.

Many input data such as biological, sociological, topographic etc. can be used in the managing and planning of forests (Bettinger et al., 2010). One of the most important factor that affects the cost of forestry activities applied in large areas is the accuracy and precision of the data to be used in the 
planning stage (Duvemo and Lämås, 2006). In this context, it is very important to model the topographical variabilities as accurately as possible, that directly affects forestry activities.

DEMs can be produced using stereo-photogrammetry, field surveys, radar (Radio Detection and Ranging) and LiDAR (Light Detection and Ranging) based techniques and technologies (Fleming et al., 2010). Each of the techniques or technologies has its own pros and cons. Although DEM generation can be accomplished using the methods listed above, contour lines, which are an inexpensive data source for large-area studies, are still used in most countries to generate DEMs (Oky Dicky Ardiansyah and Yokoyama, 2002; Li et al., 2017). A contoured topographic map presents terrain elevation and morphological information with contour lines and is the most common way to represent the terrain ( $\mathrm{Li}$ et al., 2005). In DEM production based on the contour line, an interpolation technique must be used to model the areas between the lines. From past to present, many interpolation techniques are discussed for DEM generation or 3d surface modelling in literature (Hardy, 1971; Briggs, 1974; Makarovic, 1977; Akima, 1978; Hutchinson and Bischof, 1983; Makarovic, 1984; Fortune, 1987; Hutchinson, 1989; Watson, 1992; Mitas and Mitasova, 1999). But there seems to be no single interpolation method that is the most accurate or universal for all kinds of data sources, terrain patterns, or purposes for the interpolation of terrain data (Fisher and Tate, 2006; Liu, 2008; Yurtseven et al., 2019). However Bater and Coops (2009) showed that with using of the linear, natural neighbor, quintic, spline with tension, and ANUDEM (Australian National University DEM) interpolation techniques have better representations of the terrain and more accurate parameterizations than some of the other interpolation approaches.

Generally, in large-area forestry studies, standard topomap contour lines -based DEMs or the spaceborne SRTM (Shuttle Radar Topography Mission), ASTER (Advanced Space-borne Thermal Emission and Reflection Radiometer) GDEM (Global Digital Elevation Model) data are used to obtain the topographic metrics (Aydın and Tecimen, 2010; Jing et al., 2014; Wong et al., 2014; De Meij et al., 2015; Mo et al., 2015; Rather et al., 2018).

With the increase in DEM data from various sources, users need to select the most appropriate DEM for a given application. In addition, during data processing, users are required to perform analyzes taking into account the data characteristics. Therefore, the aim of this study is to evaluate the effects of different data sources, different resolutions and different interpolation parameters on DEM derived metrics for large-area forestry applications. In this context, the two low-resolution DEM data sources (contour line based DEMs and ASTER GDEM) which are frequently used in forestry studies were compared with a state of art high-resolution LiDAR -based DEM data and the differences on some topographic metrics were evaluated. Initially, for these data sets, the pixel-based differences and the areal and volumetric differences between surface models were calculated. Thus, the differences between LiDAR -based DEM dataset, which is accepted as reference, and other DEM datasets were determined.

Slope and aspect are two of the most important topographic metrics affecting natural processes, applications and costs in forestry (Aruga et al., 2007; Gonga-Saholiariliva et al., 2011; Fernández-Landa et al., 2018; Lidberg et al., 2019). In this context, the area of the slope and aspect classes and the areal differences from the reference dataset were calculated for each data set. All results are discussed in terms of forestry, topography and data accuracy, and it is aimed to give researchers, operators and decision makers an idea in the selection of the optimal data to be used in their studies. 


\section{Material and methods}

\section{Study area}

The research area is covered the northern part of Istanbul University's Education Research and Practice Forest close to Sariyer, Istanbul. The research field is at Thracian side of the Marmara Region between $28^{\circ} 59^{\prime} 17^{\prime \prime}-29^{\circ} 32^{\prime} 25^{\prime \prime}$ east longitudes and $41^{\circ} 09^{\prime} 15^{\prime \prime}-41^{\circ} 11^{\prime} 01^{\prime \prime}$ north latitudes according to Greenwich (Figure 1). The study area dimension is approximately $2724.16 \mathrm{~m}$ wide and $4006.86 \mathrm{~m}$ long, which covers an area of 1091.53 ha. According to the LiDAR based DEM data, the elevations range from $7.55 \mathrm{~m}$ up to over $237.17 \mathrm{~m}$ above sea level.

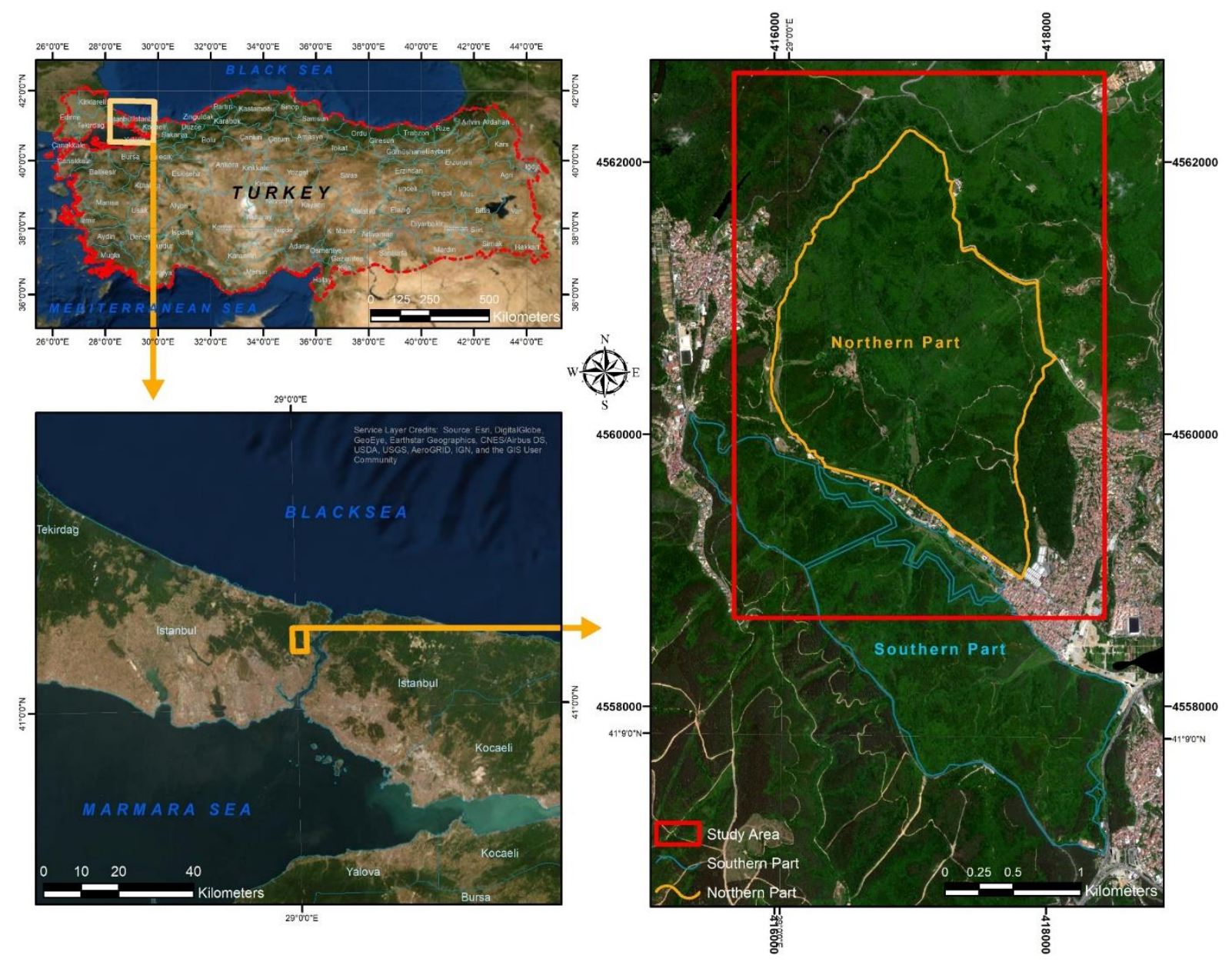

Figure 1. Study area.

\section{DEM generation}

In this study, topomap contour lines (-based DEMs), ASTER GDEM and LiDAR-based DEM data were employed (Figure 2). ASTER is one of five sensors and the only high spatial resolution instrument on the NASA's (National Aeronautics and Space Administration) Terra platform. ASTER is a result of the collaboration between NASA, Japan's Ministry of Economy, Trade and Industry (METI), and Japan Space Systems. As a result of this cooperation, ASTER products are freely available pursuant to an agreement between METI and NASA. ASTER GDEM version 2 (GDEM V2) product is generated using in-track stereo (nadir-viewing and backward-viewing) near infrared (VNIR) sensor imagery. ASTER GDEM V2 is organized according to a regular grid of 1 arc second (approximately 30 meters at the equator) and referenced to the 1984 World Geodetic System (WGS84)/1996 Earth Gravitational Model (EGM96) geoid (Tachikawa et al., 2011). 

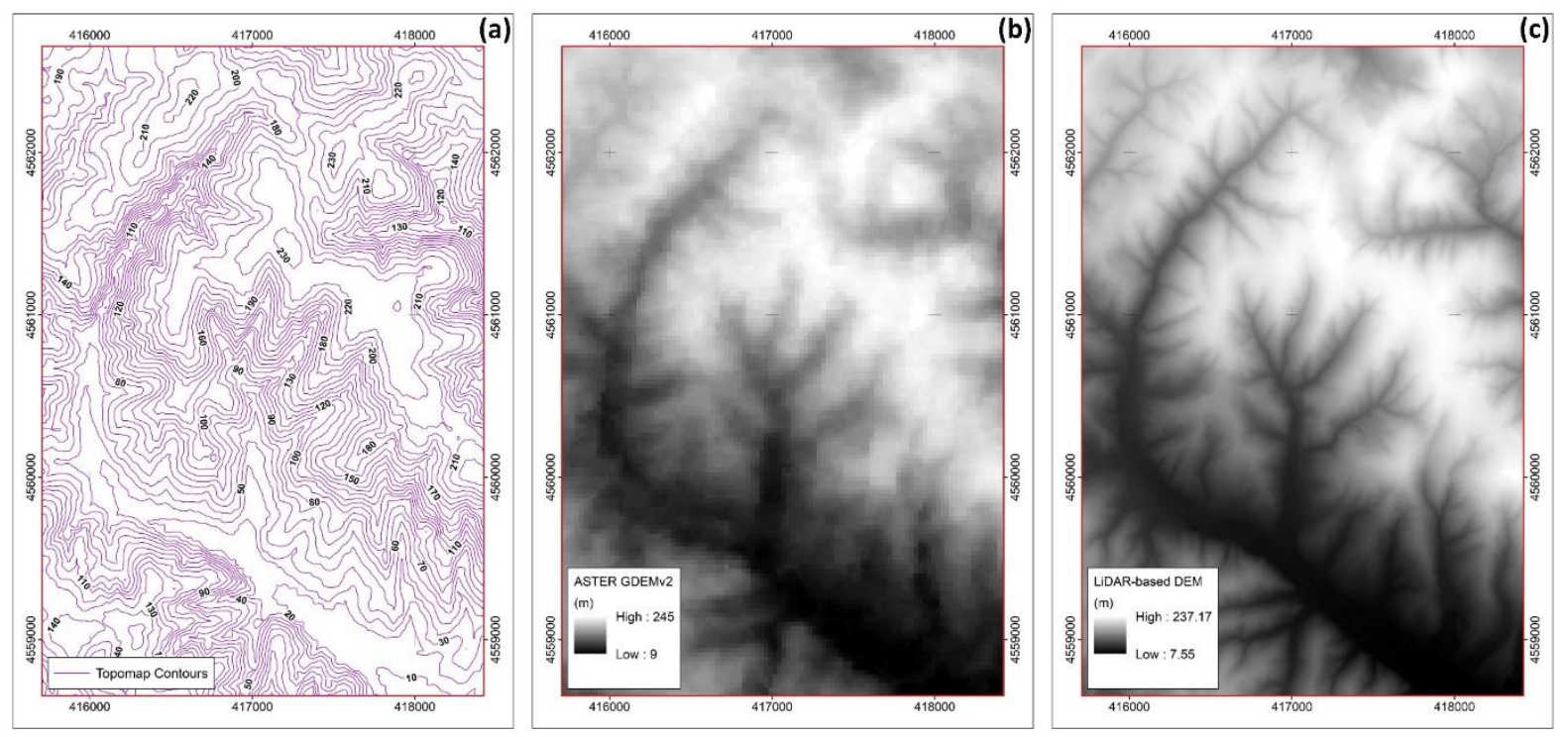

Figure 2. Topomap contour lines (a), ASTER GDEMv2 (b) and LiDAR-based DEM (c) data.

LiDAR-based DEM data were generated by the Greater Municipality of Istanbul with $0.25 \mathrm{~m}$ resolution. The point density of the raw point cloud data obtained by the Riegl Q680i laser scanner is approximately 16 points $/ \mathrm{m}^{2}$. The production of bare-earth DEM from the LiDAR point cloud involves two main steps: ground filtering and processing of filtered ground points in an interpolation routine (Aryal et al., 2017). In the separating the ground and non-ground points, TIN, slope, interpolation, segmentation, morphological or interpretation -based approaches are widely used (Dragos and Karstenb, 2008; Polat and Uysal, 2015; Dong and Chen, 2017).

In the contour lines -based DEM production, contour lines (10 m interval) of 1:25000 scale aerial photogrammetry based standard topographical maps were used which are produced by National General Directorate of Mapping (General Directorate of Mapping, 2019). 1/25000 scale topomaps are frequently used in the forestry activities in Turkey. In this study, grid based DEMs are generated from contour lines by using TIN and ANUDEM based approaches.

The TIN method is frequently used in the production of DEM from contour lines. The TIN model represents a topographic surface with non-overlapping triangular polygons (Robinson et al., 2009). Therefore, triangular-based surface modeling is a viable approach in any data model, such as regular grid sampling or contouring. However, grid-based models have many advantages in terms of data processing (Li et al., 2005). In this context, the TIN model was transformed into grid-based models using linear (Lin) and natural neighbor (NN) interpolation processes.

Also in this study, the ANUDEM algorithm was used for DEM production due to its superiority. This algorithm removes spurious depressions in the fitted DEM, in recognition of the fact that sinks are usually quite rare in nature (Band, 1986; Goodchild and Mark, 1987). This method is iterative, employing a finite difference interpolation algorithm can use both point, line and polygon data to generate DEMs with realistic drainage characteristics. Compared to other interpolation routines significantly improve the drainage quality and overall structure of the fitted DEM, especially in data sparse areas. The procedure couples a drainage enforcement algorithm with a finite difference interpolation technique (Hutchinson, 1989, 1996; Wilson and Gallant, 2000; Bater and Coops, 2009). When the drainage enforcement is on, the algorithm attempts to remove all sinks it encounters. Enforce with sink option requires some user-defined tolerances or sink data entries. Any sink that is not defined 
in the input data is considered spurious and the algorithm tries to fill it. If the drainage enforcement option is off, no sink is filled (Hutchinson et al., 2011).

The choice of the optimal grid resolution is an ongoing research topic and related to many different factors such as the point density, spatial accuracy of points, size of the area, processing power of the computer, geometry of the point patterns, complexity of the terrain, cartographic standards, and gridding or interpolation technique requirements (Hengl, 2006; Bater and Coops, 2009; Yurtseven, 2019). These factors can also affect slope and aspect mapping when determining DEM quality (Chang and Tsai, 1991).

In this context, grid resolution was determined by Nyquist frequency concept (Nyquist, 1924; Shannon, 1934). This concept is based on signal theory and indicates that the resolution of the grid should be at most half of the mean distance between the nearest point pairs $\left(\bar{d}_{\text {mean }}\right)(\mathrm{Hengl}, 2006)$.

$$
\text { Res. } \leq \frac{\bar{d}_{\text {mean }}}{2}
$$

Table 1. ANUDEM -based DEMs properties.

\begin{tabular}{cccc}
\hline DEM dataset & $\begin{array}{c}\text { Resolution } \\
(\mathbf{m})\end{array}$ & $\begin{array}{c}\text { Drainage } \\
\text { Enforcement }\end{array}$ & $\begin{array}{c}\text { The Dominant } \\
\text { Elevation Data Type }\end{array}$ \\
\hline Anudem_001 & 2.5 & On & Contour \\
Anudem_002 & 2.5 & On with Sink & Contour \\
Anudem_003 & 2.5 & Off & Contour \\
Anudem_004 & 2.5 & On & Point \\
Anudem_005 & 2.5 & On with Sink & Point \\
Anudem_006 & 2.5 & Off & Point \\
Anudem_007 & 5 & On & Contour \\
Anudem_008 & 5 & On with Sink & Contour \\
Anudem_009 & 5 & Off & Contour \\
Anudem_010 & 5 & On & Point \\
Anudem_011 & 5 & On with Sink & Point \\
Anudem_012 & 5 & Off & Point \\
Anudem_013 & 10 & On & Contour \\
Anudem_014 & 10 & On with Sink & Contour \\
Anudem_015 & 10 & Off & Contour \\
Anudem_016 & 10 & On & Point \\
Anudem_017 & 10 & On with Sink & Point \\
Anudem_018 & 10 & Off & Point \\
Anudem_019 & 30 & On & Contour \\
Anudem_020 & 30 & On with Sink & Contour \\
Anudem_021 & 30 & Off & Contour \\
Anudem_022 & 30 & On & Point \\
Anudem_023 & 30 & On with Sink & Point \\
Anudem_024 & 30 & Off & Point \\
\hline
\end{tabular}

When the contour line data used in the study were analyzed, it was found that the mean, minimum and maximum horizontal distances between the contour lines were $10.69 \mathrm{~m}, 4.92 \mathrm{~m}$ and $29.02 \mathrm{~m}$, 
respectively. In this context, finest resolution was accepted as $2.5 \mathrm{~m}$ (half of the minimum horizontal distance). Also, $5 \mathrm{~m}$ (half of the mean horizontal distance) and $10 \mathrm{~m}$ resolutions were accepted in order to observe the effect of changes in resolution on the results of the analysis. In addition, the $30 \mathrm{~m}$ resolution offered by ASTER data was considered to be included in the study in order to compare the results. Thus, the use of four different resolutions was accepted in the production of interpolation-based DEM from contour lines data.

In this study, 32 interpolation -based DEM generated from topomap contour lines, with below mentioned parameters (Table 1, Table 2 and Figure 3). In total, 34 DEMs were used (including LiDAR based DEM) and 33 of them were analyzed.

Table 2. TIN to Raster -based DEMs properties.

\begin{tabular}{ccc}
\hline DEM dataset & $\begin{array}{c}\text { Resolution } \\
(\mathbf{m})\end{array}$ & Interpolator \\
\hline Tin_to_Raster_001 & 2.5 & Linear \\
Tin_to_Raster_002 & 2.5 & Natural Neighbor \\
Tin_to_Raster_003 & 5 & Linear \\
Tin_to_Raster_004 & 5 & Natural Neighbor \\
Tin_to_Raster_005 & 10 & Linear \\
Tin_to_Raster_006 & 10 & Natural Neighbor \\
Tin_to_Raster_007 & 30 & Linear \\
Tin_to_Raster_008 & 30 & Natural Neighbor \\
\hline
\end{tabular}

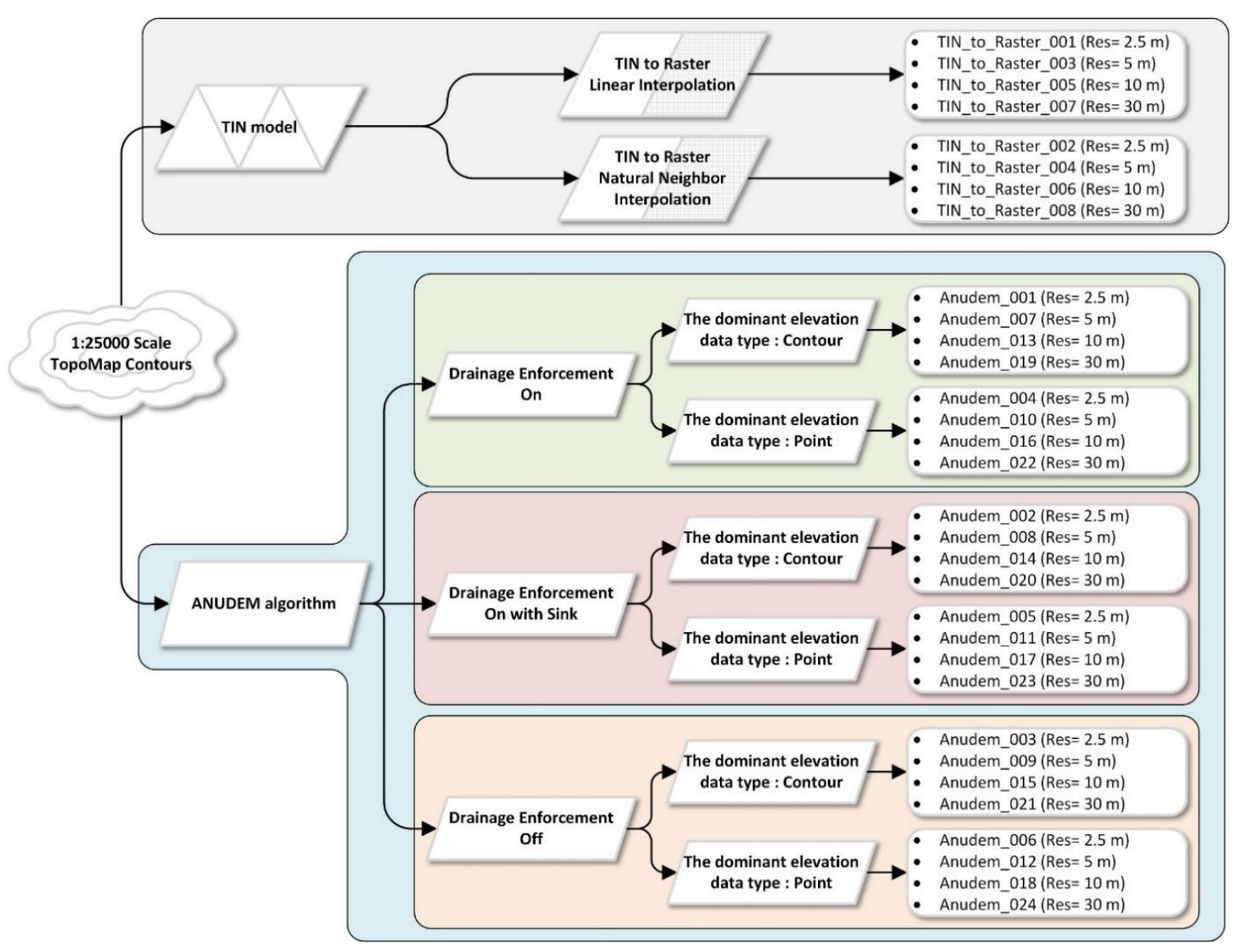

Figure 3. Contour -based DEM generation strategy. 


\section{Comparison Methodology}

The coordinate system of the study is accepted as ED 1950 TM30 (EPSG: 2320). In order to perform a comparison horizontal and vertical coordinate transformations are performed for each datasets. After generating the surface models, data comparison procedures were performed. In this context, LiDAR based DEM and -derived datasets are accepted as reference.

In this stage, surface model, slope and aspect -based differences from the reference data were investigated. The surface -based evaluations were performed by calculating the pixel-based surface differences and evaluating the areal and volumetric differences of the DEMs. Pixel-based surface differences, ie, vertical residues, were calculated to determine the differences of each dataset from LiDAR -based DEM. In this context, descriptive statistics, mean differences, mean absolute differences and root mean square (RMS) differences were calculated and used as accuracy measures.

$$
\begin{aligned}
& \operatorname{Mean} \operatorname{Diff} \cdot(Z)=\frac{1}{n} \sum_{i=1}^{n}\left(Z_{E v a(i)}-Z_{R e f(i)}\right) \\
& \operatorname{Mean} \text { Abs.Diff }_{\cdot(Z)}=\frac{1}{n} \sum_{i=1}^{n}\left(\left|Z_{E v a(i)}-Z_{R e f(i)}\right|\right) \\
& \operatorname{RMS~Diff}_{\cdot(Z)}=\sqrt{\frac{1}{n} \sum_{i=1}^{n}\left(Z_{E v a(i)}-Z_{R e f(i)}\right)^{2}}
\end{aligned}
$$

To determine the areal and volumetric differences among the DEMs, the false positive, false negative, no difference, absolute difference zones and absolute difference volume per area were calculated for each datasets. In this context, the false positive defines the zones where the evaluated-reference difference is positive, and the false negative defines the zones where the evaluated-reference difference is negative (Figure 4) (Yurtseven, 2019).
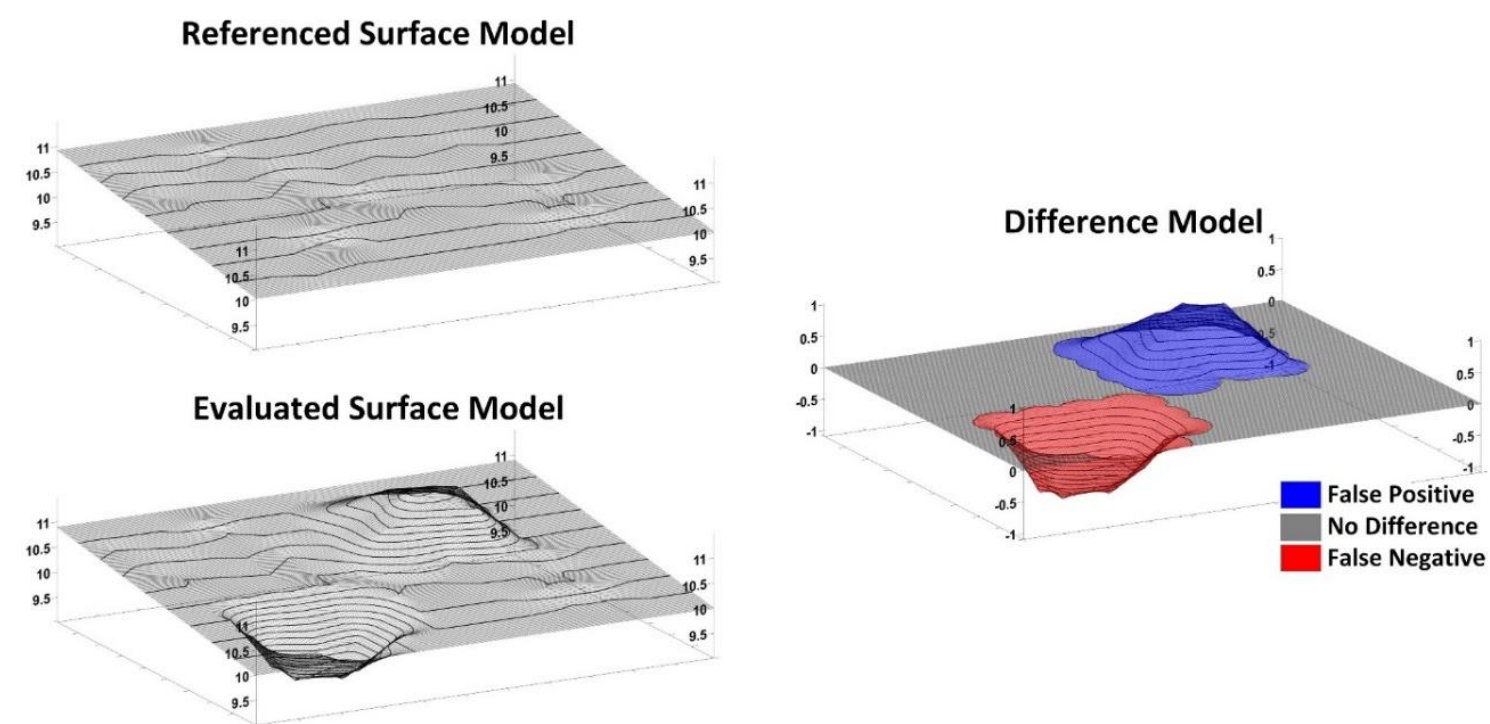

Figure 4. Visual definition of false positive, false negative and no difference areas and volumes. 
The slope and aspect -based areal differences were evaluated on a class basis. The inclination of slope data was calculated as percent rise and slope data were analyzed in 11 classes (Table 3a). The aspect data were analyzed in 9 classes including 4 cardinal, 4 intercardinal directions and flat land (Table $3 b$ ).

Table 3. Slope (a) and aspect (b) classes.

\begin{tabular}{|c|c|c|c|}
\hline \multicolumn{2}{|c|}{ Slope Classification } & \multicolumn{2}{|c|}{ Aspect Classification } \\
\hline Slope classes & Slope gradient (\%) & Aspect classes & Aspect gradient $\left(^{\circ}\right)$ \\
\hline 1 & $<5$ & Flat & -1 \\
\hline 2 & $5-10$ & North & $0-22.5,337.5-360$ \\
\hline 3 & $10-15$ & Northeast & $22.5-67.5$ \\
\hline 4 & $15-20$ & East & $67.5-112.5$ \\
\hline 5 & $20-30$ & Southeast & $112.5-157.5$ \\
\hline 6 & $30-40$ & South & $157.5-202.5$ \\
\hline 7 & $40-50$ & Southwest & $202.5-247.5$ \\
\hline 8 & $50-60$ & West & $247.5-292.5$ \\
\hline 9 & $60-80$ & NorthWest & $292.5-337.5$ \\
\hline 10 & $80-100$ & & \\
\hline 11 & $100<$ & & \\
\hline
\end{tabular}

\section{Results and Discussion}

In the contour lines -based DEM production, TIN and ANUDEM -based approaches were used. By systematically differentiating the parameters of the two interpolation procedures, 32 DEMs were generated at four different resolutions from the contour line dataset. In total 33 DEMs, including ASTER GDEMv2 were analyzed (Appendix 1-DEM Datasets). For all interpolation algorithms and all spatial resolutions, global pixel-based difference statistics from LiDAR-based DEM are presented in Table 4 and Figure 5. Also difference DEMs are presented in Appendix 2-Difference DEMs. While the mean difference for all of the datasets except for the ASTER dataset were sub-meter, the difference range vary between 63.23 and $84.50 \mathrm{~m}$, and the standard deviation of difference ranged from 4.72 to $9.53 \mathrm{~m}$. Generally all the global difference metrics are increasing for all interpolation routines as spatial resolution increased from 30 to $2.5 \mathrm{~m}$. At lower resolutions (10 and $30 \mathrm{~m}$ ) ANUDEM-based DEMs showed better parameterization, while at higher resolutions $(2.5$ and $5 \mathrm{~m})$ the situation was similar for the TIN to raster and ANUDEM -based approaches. All metric values were consistent for all interpolation routines up to $30 \mathrm{~m}$ resolution. For $30 \mathrm{~m}$ resolution, the mean differences submitted the lowest, the difference ranges and the standard deviations submitted the highest values.

TIN-derived DEMs contain directional surfaces at all resolutions. The ANUDEM algorithm generated surfaces which were smooth and represent the topography better (Figure 6). However, DEMs generated using both ANUDEM and TIN based interpolators particularly at higher resolutions, have topographic steps due to the use of contour line data as the base.

The mean and RMS differences of ASTER GDEM v2 from LiDAR -based DEM in our study region are $7.39 \mathrm{~m}$ and $11.10 \mathrm{~m}$, respectively. According to Tachikawa et al. (2011), the planned mean errors for the GDEM v2 is -0.2 m.. Mukherjee et al. (2013), Rexer and Hirt (2014) and Szabó et al. (2015) reported that the vertical error of ASTER GDEM v2 is $2.7 \mathrm{~m}$ with $9.1 \mathrm{~m}$ RMSE, $2.58 \mathrm{~m}$ with $9.2 \mathrm{~m}$ RMSE and $-4.2 \mathrm{~m}$ with $9.2 \mathrm{~m}$ RMSE, respectively. 
It can be considered that there are some reasons for the occurrence of such a difference from previous studies. As is known, stereo-correlations are more difficult in forest areas due to the textural properties of vegetation-covered surfaces and their low color contrast. Therefore, fewer points meet threshold correlation criteria, and this kind of surfaces are represented by lower point densities and lower accuracy rates in the photogrammetric model.

Topomap contour lines and ASTER GDEM data used in the study were produced by using photogrammetric techniques. In this context, contour lines are generated by manual interpretation using stereoscopic models. In the stereoscopic model, aerial imagery are used. ASTER DEM data is generated by automated techniques using stereoscopic image matching algorithms on satellite imagery. Both methods have advantages and disadvantages. In this context, interpretation based errors, atmospheric effects (haze, lightning conditions), spatial accuracy of stereoscopic models, etc. can be attributed as error sources.

Table 4. Global difference statistics from LiDAR-based DEM.

\begin{tabular}{|c|c|c|c|c|c|c|c|c|}
\hline DEM dataset & $\begin{array}{l}\text { Res. } \\
\text { (m) }\end{array}$ & $\begin{array}{l}\text { Mean Diff. } \\
\quad(\mathrm{m})\end{array}$ & $\begin{array}{l}\text { Min Diff. } \\
\text { (m) }\end{array}$ & $\begin{array}{l}\text { Max Diff. } \\
\quad(\mathrm{m})\end{array}$ & $\begin{array}{c}\text { Diff. Range } \\
\text { (m) }\end{array}$ & $\begin{array}{l}\text { Std. Dev. } \\
\text { of Diff. } \\
\text { (m) }\end{array}$ & $\begin{array}{c}\text { Mean } \\
\text { Absolute } \\
\text { Diff. (m) }\end{array}$ & $\begin{array}{c}\text { RMS } \\
\text { Diff. } \\
\text { (m) }\end{array}$ \\
\hline Anudem_001 & 2.5 & 0.71 & -34.26 & 30.53 & 64.79 & 4.72 & 3.42 & 4.78 \\
\hline Anudem_002 & 2.5 & 0.71 & -34.26 & 30.53 & 64.79 & 4.72 & 3.42 & 4.78 \\
\hline Anudem_003 & 2.5 & 0.72 & -34.26 & 30.64 & 64.90 & 4.73 & 3.43 & 4.79 \\
\hline Anudem_004 & 2.5 & 0.54 & -34.26 & 30.14 & 64.40 & 4.88 & 3.58 & 4.91 \\
\hline Anudem_005 & 2.5 & 0.65 & -34.26 & 30.40 & 64.66 & 4.95 & 3.66 & 4.99 \\
\hline Anudem_006 & 2.5 & 0.65 & -34.26 & 30.40 & 64.66 & 4.95 & 3.66 & 4.99 \\
\hline Tin_to_Raster_001 & 2.5 & 0.66 & -34.07 & 30.29 & 64.36 & 5.04 & 3.75 & 5.08 \\
\hline Tin_to_Raster_002 & 2.5 & 0.64 & -33.98 & 30.29 & 64.27 & 5.04 & 3.75 & 5.08 \\
\hline Anudem_007 & 5 & 0.67 & -35.57 & 28.93 & 64.50 & 5.01 & 3.66 & 5.06 \\
\hline Anudem_008 & 5 & 0.67 & -35.57 & 28.93 & 64.50 & 5.01 & 3.66 & 5.06 \\
\hline Anudem_009 & 5 & 0.67 & -35.57 & 29.01 & 64.58 & 5.02 & 3.67 & 5.06 \\
\hline Anudem_010 & 5 & 0.51 & -35.59 & 28.24 & 63.83 & 5.15 & 3.80 & 5.17 \\
\hline Anudem_011 & 5 & 0.61 & -35.59 & 29.08 & 64.67 & 5.20 & 3.87 & 5.24 \\
\hline Anudem_012 & 5 & 0.61 & -35.59 & 29.08 & 64.67 & 5.20 & 3.87 & 5.24 \\
\hline Tin_to_Raster_003 & 5 & 0.65 & -34.97 & 30.48 & 65.46 & 5.15 & 3.84 & 5.19 \\
\hline Tin_to_Raster_004 & 5 & 0.63 & -34.85 & 30.48 & 65.33 & 5.15 & 3.85 & 5.18 \\
\hline Anudem_013 & 10 & 0.55 & -38.05 & 27.26 & 65.31 & 5.74 & 4.26 & 5.76 \\
\hline Anudem_014 & 10 & 0.55 & -38.05 & 27.26 & 65.31 & 5.74 & 4.26 & 5.88 \\
\hline Anudem_015 & 10 & 0.55 & -38.05 & 27.26 & 65.32 & 5.74 & 4.27 & 5.77 \\
\hline Anudem_016 & 10 & 0.42 & -38.02 & 27.26 & 65.28 & 5.83 & 4.36 & 5.84 \\
\hline Anudem_017 & 10 & 0.50 & -38.02 & 27.35 & 65.37 & 5.86 & 4.41 & 5.76 \\
\hline Anudem_018 & 10 & 0.50 & -38.02 & 27.35 & 65.37 & 5.86 & 4.41 & 5.88 \\
\hline Tin_to_Raster_005 & 10 & 0.59 & -36.63 & 27.80 & 64.43 & 5.37 & 4.03 & 5.40 \\
\hline Tin_to_Raster_006 & 10 & 0.57 & -36.42 & 26.80 & 63.23 & 5.36 & 4.03 & 5.39 \\
\hline Anudem_019 & 30 & 0.09 & -46.79 & 37.58 & 84.37 & 9.52 & 7.27 & 9.52 \\
\hline Anudem_020 & 30 & 0.09 & -46.79 & 37.58 & 84.37 & 9.52 & 7.27 & 9.52 \\
\hline Anudem_021 & 30 & 0.08 & -46.79 & 37.59 & 84.38 & 9.53 & 7.27 & 9.53 \\
\hline Anudem_022 & 30 & 0.06 & -46.67 & 37.80 & 84.47 & 9.53 & 7.29 & 9.53 \\
\hline Anudem_023 & 30 & 0.08 & -46.68 & 37.82 & 84.50 & 9.53 & 7.31 & 9.53 \\
\hline Anudem_024 & 30 & 0.08 & -46.68 & 37.82 & 84.50 & 9.53 & 7.31 & 9.53 \\
\hline Tin_to_Raster_007 & 30 & 0.42 & -39.15 & 30.27 & 69.42 & 6.77 & 5.12 & 6.78 \\
\hline Tin_to_Raster_008 & 30 & 0.40 & -39.15 & 30.27 & 69.42 & 6.76 & 5.12 & 6.77 \\
\hline Aster & 30 & 7.39 & -28.46 & 48.19 & 76.65 & 8.29 & 8.91 & 11.10 \\
\hline
\end{tabular}




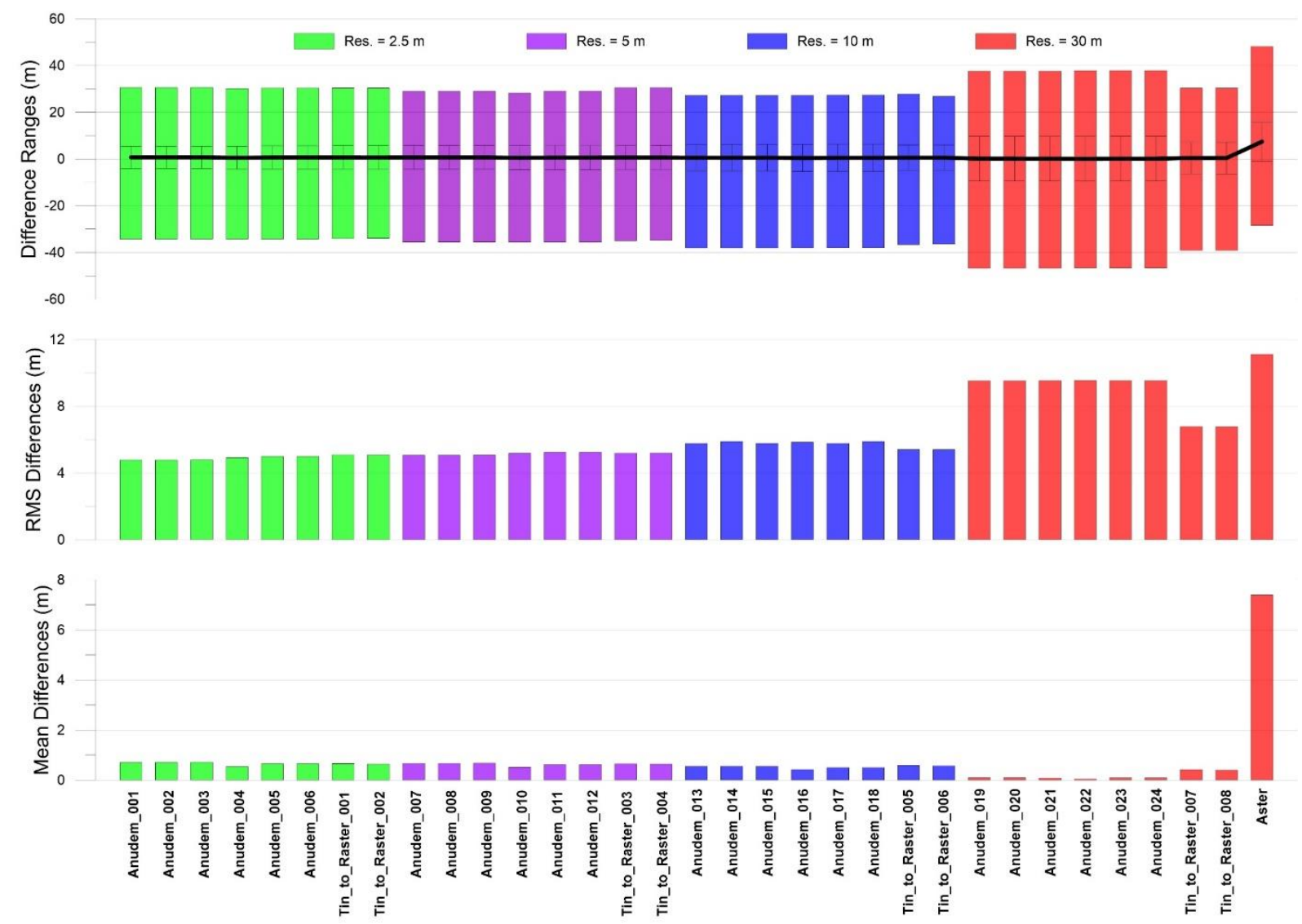

Figure 5. Global difference statistics.

Also, the purpose of manual interpretation is to produce topographic information about the bare soil surface; ASTER GDEM data presents a model with topography of man-made objects (such as structure) and vegetation. The study area is mostly covered with forest. In this context, the mean positive difference value of $7.39 \mathrm{~m}$ presented by ASTER data is significant because the reference data set has bare-earth topographic information. However, this can only be an explanation for positive values. Since LiDAR data is generated using laser-based detection techniques, the data generated from both data sources is never reached the details provided by the LiDAR data. Therefore, local topographic variability can be modeled more accurately with LiDAR data. In this context, negative values were attributed to the inability of both datasets to reach the high detail and resolution presented by the LiDAR data.

The areal and volumetric difference analyses were performed for the ANUDEM, TIN and ASTER based DEMs. In this context, the false positive (F.P.), false negative (F.N) and the no difference zones from LiDAR-based DEM were determined for each datasets (Appendix 3-DEM Difference Zones). The total (T. Diff.) and absolute total (A.T. Diff.) areal and volumetric differences were also calculated (Table 5 and Figure 7). 

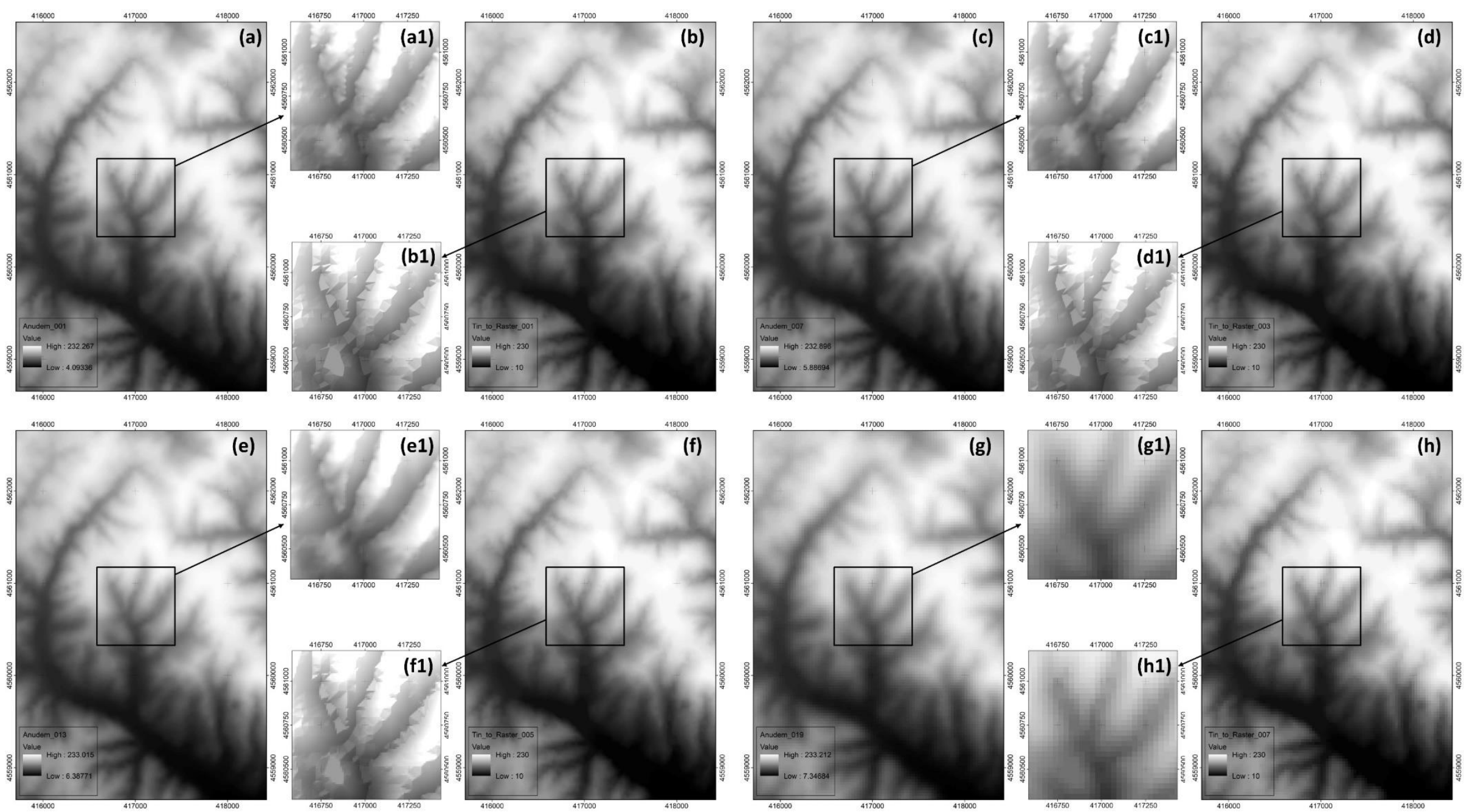

Figure 6. 1:25000 scale contour line - based DEM visuals. Resolution $=2.5 \mathrm{~m}$; Anudem 001 (a, a1), Tin to Raster $001(\mathrm{~b}, \mathrm{~b} 1)$. Resolution $=5 \mathrm{~m} ;$ Anudem $007(\mathrm{c}, \mathrm{c} 1)$, Tin_to_Raster_003 (d, d1). Resolution = $10 \mathrm{~m}$; Anudem_013 (e, e1), Tin_to_Raster_005 (f, f1). Resolution = 30 m; Anudem_019 (g, g1), Tin_to_Raster_007 (h, h1). 
Table 5. Volumetric and areal differences from LiDAR-based DEM.

\begin{tabular}{|c|c|c|c|c|c|c|c|c|c|c|c|}
\hline \multirow[b]{2}{*}{ DEM dataset } & \multirow[b]{2}{*}{ 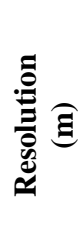 } & \multicolumn{5}{|c|}{ Area (ha) } & \multicolumn{4}{|c|}{ Volume $\left(\mathrm{m}^{3} \times 10^{6}\right)$} & \multirow{2}{*}{ 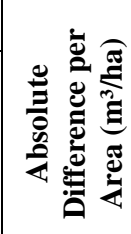 } \\
\hline & & 氙 & 总: & 之窇 & 焉窇 & 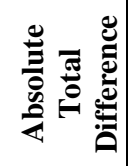 & 氙 & 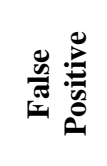 & 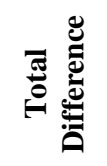 & 总 & \\
\hline & 2.5 & 06.25 & 583.48 & 0.00 & 77.23 & 1089.73 & 14.220 & 22.182 & 7.962 & 36.401 & 33403.97 \\
\hline Anudem_002 & 2.5 & & 583.48 & 0.00 & & & & 22.182 & & & \\
\hline Anudem_003 & 2.5 & & 584.27 & 0.00 & & & 14.238 & 22.278 & & & \\
\hline & 2.5 & 3.58 & 566.15 & 0.00 & & 1089.73 & 16.019 & 22.107 & 6.089 & 38.126 & \\
\hline Anud & 2.5 & 0.42 & 579.31 & 0.00 & & 1089.73 & 15.872 & 23.225 & 7.352 & 39.097 & \\
\hline Anud & 2.5 & & 579 & 0.00 & & & & 23.225 & & & \\
\hline Tin_to_ & 2.5 & & 581.14 & 0.16 & & & & 23.851 & & & \\
\hline & 2.5 & & 578 & 0.13 & & & & 23.795 & & & \\
\hline & 5 & & 580 & 0.00 & & & & 22.276 & & & \\
\hline & 5 & & 580.95 & 0.00 & & 1089.73 & & 22.276 & & & \\
\hline & 5 & & 581.22 & & & & 14.695 & 22.348 & & & \\
\hline & 5 & 3.01 & 566.7 & 0.00 & & & 16. & 22.235 & & & \\
\hline & 5 & 1.67 & 578.05 & 0.00 & & 1089.73 & 16.218 & 23.218 & & & \\
\hline & 5 & & & & & & & 23.218 & & & \\
\hline & 5 & & 581.35 & 0.16 & & & & 23. & 7.3 & & \\
\hline & 5 & 1.03 & 578.57 & 0.14 & & 1089.60 & 16.565 & 23.784 & & & \\
\hline & 10 & & 577.17 & & & & & 22.954 & & & \\
\hline & 10 & 2.57 & 577.17 & 0.00 & 64.60 & 9.73 & 15.946 & 22.9 & 7.008 & .900 & \\
\hline & 10 & 513.24 & 576.50 & 0.00 & 63.26 & 1089.73 & 15.986 & 22.999 & 7.012 & 38.985 & \\
\hline & 10 & & & & & & & 22.937 & & & \\
\hline & 10 & 15.85 & 573.89 & 0.00 & 58.04 & 1089.73 & 17.274 & 23.715 & 6.441 & 40.989 & \\
\hline & 10 & 15.85 & 573.89 & 0.00 & 58.04 & 1089.73 & 17.274 & 23.715 & 6.441 & 40.989 & \\
\hline & 10 & & & & & & & & & & \\
\hline Tin_to_R & 10 & 511.54 & 578.07 & 0.12 & 66.53 & 1089.61 & 16.531 & 23.789 & 7.257 & 40.320 & 37004.11 \\
\hline & 30 & 532.36 & 557.38 & 0.00 & & & 26.059 & 29.753 & & 55.812 & \\
\hline & 30 & & & 0.00 & & & & 29.753 & & & \\
\hline Anudem_021 & 30 & 534.16 & 555.58 & 0.00 & 21.42 & 1089.73 & 26.164 & 29.723 & 3.559 & 55.886 & 51284.71 \\
\hline & 30 & 537.31 & 552.43 & 0.00 & 15.12 & & 26.638 & 29.947 & 3.309 & 56.585 & 51925.55 \\
\hline Anuden & 30 & 532.36 & 557.38 & 0.00 & 25.02 & & 26.656 & 30.286 & 3.630 & 56.942 & \\
\hline Anudem_024 & 30 & 532.36 & 557.38 & 0.00 & 25.02 & 1089.73 & 26.656 & 30.286 & 3.630 & 56.942 & 52253.41 \\
\hline Tin_to_R & 30 & 509.41 & 580.15 & 0.18 & 70.74 & 1089.55 & 16.579 & 23.871 & 7.291 & 40.450 & 37125.35 \\
\hline Tin_to_Raster_008 & 30 & 513.73 & 575.83 & 0.18 & 62.10 & 1089.55 & 16.674 & 23.795 & & 40.469 & 37143.22 \\
\hline Aster & 30 & 153.26 & 936.25 & 0.22 & 782.98 & 1089.51 & 6.162 & 89.569 & 83.407 & 95.731 & 87866.40 \\
\hline
\end{tabular}

The areal and volumetric difference analysis results indicated that TIN to Raster -based DEMs delivered the most consistent results at all resolutions. ASTER GDEMv2 has the worst results as can be predicted from the difference statistics. When the analysis results were interpreted, it was found that the false positive values were slightly higher than the false negative values for areal differences. On the other hand, the situation in volumetric differences is considerable. The false positive values for volumetric differences were approximately $7 \mathrm{~m}^{3} \times 10^{6}$ higher than the false negative values, up to $30 \mathrm{~m}$ resolution both for ANUDEM and TIN -based approaches. ANUDEM-based DEMs delivered significant results up to $10 \mathrm{~m}$ resolution, whereas the difference values have increased as the resolution decreased to $30 \mathrm{~m}$. 

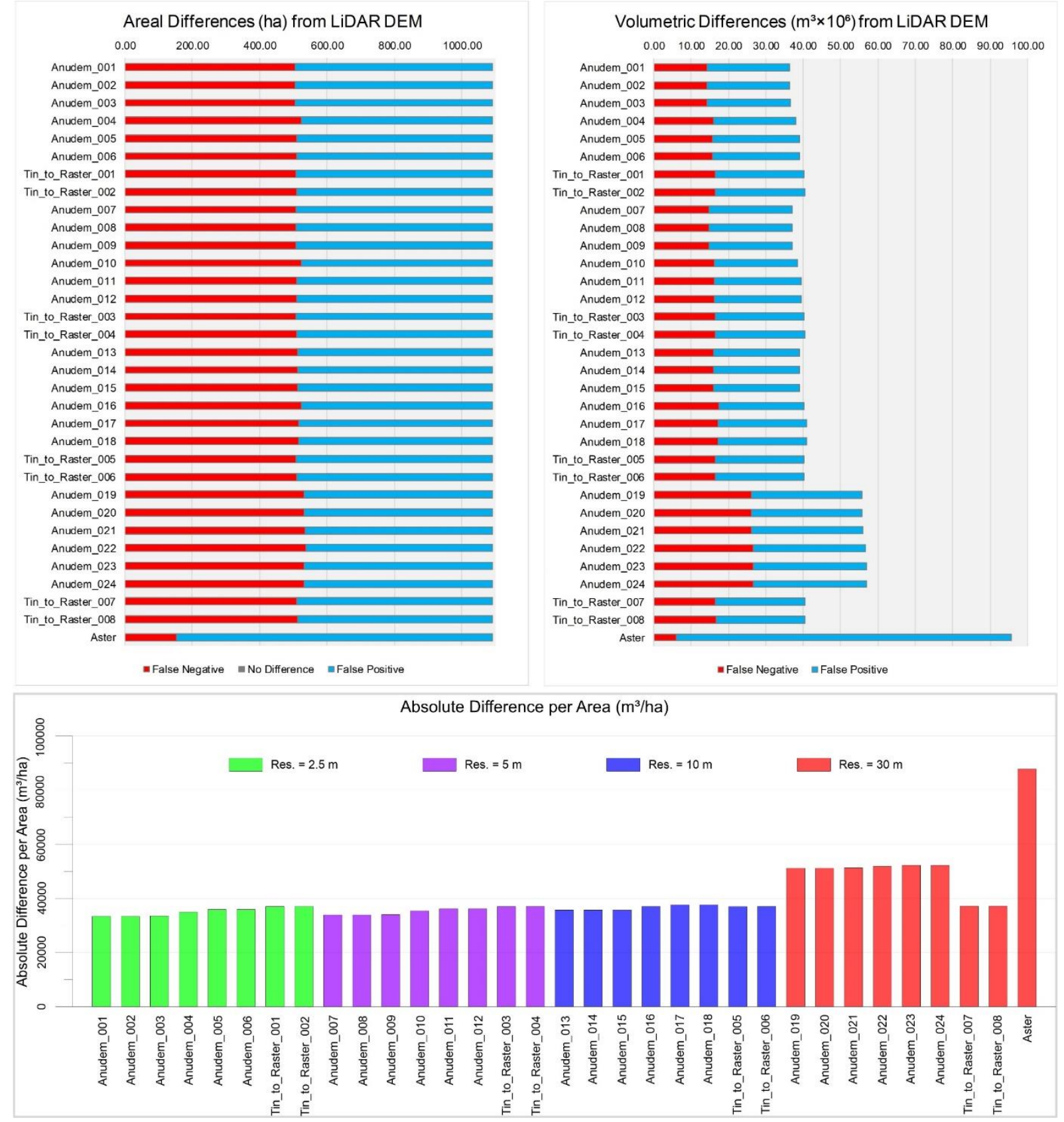

Figure 7. Areal and volumetric differences

According to the LiDAR - based DEM -derived slope data, there was a wide range of slope differences in the study area (Appendix 4-Slope Datasets, Appendix 5-Slope Dataset Statistics) and for all slope classes areal distributions were variable (Figure 8, Appendix 6-Area of Slope Classes). According to the slope statistics, the mean and the standard deviation of slope is decreased with increasing the resolution, as similarly reported by Evans (1980), Zhang et al. (1999) and Chen and Zhou (2013). When the slope difference analysis results were interpreted, it was found that the difference values up to 40-50\% slope were positive and for slope classes greater than 40-50\% were negative (Table 6). In addition, it was another considerable point that areal slope difference values tended to decrease with increasing resolution of interpolation-based DEMs (Table 6 and Figure 8). The best comparison results were obtained by "Anudem_003" dataset at all resolutions. Respectively, Anudem_009 at 5m resolution, Anudem_013-014 at 10m resolution, and ASTER datasets at 30m resolution had the best results. 
Table 6. Areal differences of Slope classes from LiDAR-based DEM.

\begin{tabular}{|c|c|c|c|c|c|c|c|c|c|c|c|c|c|}
\hline \multirow{2}{*}{ Slope dataset } & \multicolumn{11}{|c|}{ Areal Differences of Slope (\%) Classes from LiDAR-based DEM (ha) } & \multirow{2}{*}{$\begin{array}{c}\text { Std. } \\
\text { Dev. } \\
\text { of Diff. }\end{array}$} & \multirow{2}{*}{$\begin{array}{l}\text { Abs. } \\
\text { Total } \\
\text { Diff. }\end{array}$} \\
\hline & $<5$ & $5-10$ & $10-15$ & $15-20$ & $20-30$ & $30-40$ & $40-50$ & $50-60$ & $60-80$ & $80-100$ & $100<$ & & \\
\hline Anudem_001 & 20.21 & 38.41 & 31.64 & 42.00 & 65.28 & 20.18 & -26.79 & -57.35 & -89.32 & -30.09 & -14.19 & 45.13 & 435.45 \\
\hline Anudem_002 & 20.21 & 38.41 & 31.64 & 42.00 & 65.28 & 20.18 & -26.79 & -57.35 & -89.32 & -30.09 & -14.19 & 45.13 & 435.45 \\
\hline Anudem_003 & 25.33 & 36.54 & 29.43 & 41.14 & 65.37 & 19.82 & -26.82 & -57.23 & -89.28 & -30.10 & -14.19 & 45.00 & 435.24 \\
\hline Anudem_004 & 58.53 & 20.76 & 30.34 & 39.69 & 59.46 & 17.25 & -28.74 & -60.87 & -91.55 & -30.69 & -14.19 & 46.94 & 452.06 \\
\hline Anudem_005 & 92.67 & 12.84 & 20.57 & 34.45 & 52.96 & 13.89 & -30.01 & -60.97 & -91.56 & -30.65 & -14.19 & 50.00 & 454.76 \\
\hline Anudem_006 & 92.67 & 12.84 & 20.57 & 34.45 & 52.96 & 13.89 & -30.01 & -60.97 & -91.56 & -30.65 & -14.19 & 50.00 & 454.76 \\
\hline Tin_to_Raster_001 & 116.66 & -39.94 & 9.05 & 46.25 & 70.15 & 19.56 & -26.93 & -60.69 & -89.94 & -30.08 & -14.09 & 57.47 & 523.34 \\
\hline Tin_to_Raster_002 & 107.97 & -15.29 & 18.20 & 41.08 & 63.95 & 13.99 & -31.00 & -63.33 & -91.19 & -30.28 & -14.09 & 54.44 & 490.38 \\
\hline Anudem_007 & 19.70 & 37.76 & 31.44 & 40.10 & 70.97 & 26.64 & -27.63 & -60.65 & -93.28 & -30.87 & -14.19 & 47.15 & 453.24 \\
\hline Anudem_008 & 19.70 & 37.76 & 31.44 & 40.10 & 70.97 & 26.64 & -27.63 & -60.65 & -93.28 & -30.87 & -14.19 & 47.15 & 453.24 \\
\hline Anudem_009 & 24.15 & 35.10 & 29.80 & 39.87 & 71.38 & 26.57 & -27.82 & -60.63 & -93.34 & -30.90 & -14.19 & 47.11 & 453.75 \\
\hline Anudem_010 & 55.68 & 21.40 & 27.49 & 39.64 & 65.93 & 25.15 & -29.21 & -64.46 & -95.91 & -31.50 & -14.19 & 48.86 & 470.55 \\
\hline Anudem_011 & 82.86 & 13.47 & 20.57 & 36.15 & 61.32 & 22.28 & -30.26 & -64.81 & -95.91 & -31.48 & -14.19 & 50.94 & 473.29 \\
\hline Anudem_012 & 82.86 & 13.47 & 20.57 & 36.15 & 61.32 & 22.28 & -30.26 & -64.81 & -95.91 & -31.48 & -14.19 & 50.94 & 473.29 \\
\hline Tin_to_Raster_003 & 103.43 & -30.25 & 17.17 & 49.13 & 71.18 & 19.29 & -29.72 & -63.29 & -92.20 & -30.58 & -14.16 & 55.83 & 520.41 \\
\hline Tin_to_Raster_004 & 98.61 & -10.46 & 22.74 & 44.08 & 66.11 & 14.77 & -32.89 & -65.16 & -92.98 & -30.68 & -14.16 & 53.93 & 492.65 \\
\hline Anudem_013 & 20.68 & 33.06 & 33.98 & 45.87 & 78.98 & 32.95 & -32.27 & -67.44 & -99.95 & -31.66 & -14.19 & 51.25 & 491.03 \\
\hline Anudem_014 & 20.68 & 33.06 & 33.98 & 45.87 & 78.98 & 32.95 & -32.27 & -67.44 & -99.95 & -31.66 & -14.19 & 51.25 & 491.03 \\
\hline Anudem_015 & 21.41 & 31.94 & 34.52 & 46.18 & 79.06 & 32.78 & -32.72 & -67.32 & -100.02 & -31.63 & -14.19 & 51.29 & 491.77 \\
\hline Anudem_016 & 49.09 & 20.53 & 28.66 & 46.21 & 76.52 & 32.15 & -32.94 & -71.67 & -102.47 & -31.88 & -14.19 & 52.76 & 506.31 \\
\hline Anudem_017 & 65.94 & 15.11 & 25.38 & 44.16 & 74.39 & 30.01 & -34.91 & -71.60 & -102.40 & -31.88 & -14.19 & 53.64 & 509.97 \\
\hline Anudem_018 & 65.94 & 15.11 & 25.38 & 44.16 & 74.39 & 30.01 & -34.91 & -71.60 & -102.40 & -31.88 & -14.19 & 53.64 & 509.97 \\
\hline Tin_to_Raster_005 & 82.88 & -14.48 & 29.95 & 54.10 & 74.49 & 18.57 & -36.35 & -67.81 & -95.96 & -31.20 & -14.19 & 54.85 & 519.98 \\
\hline Tin_to_Raster_006 & 82.64 & -2.09 & 31.97 & 49.52 & 71.61 & 15.51 & -38.26 & -68.91 & -96.48 & -31.32 & -14.19 & 54.26 & 502.50 \\
\hline Anudem_019 & 9.00 & 37.92 & 72.00 & 90.84 & 117.55 & 4.65 & -77.76 & -94.31 & -113.83 & -31.88 & -14.19 & 72.56 & 663.94 \\
\hline Anudem_020 & 9.00 & 37.92 & 72.00 & 90.84 & 117.55 & 4.65 & -77.76 & -94.31 & -113.83 & -31.88 & -14.19 & 72.56 & 663.94 \\
\hline Anudem_021 & 7.56 & 38.01 & 74.25 & 90.48 & 117.28 & 3.66 & -77.40 & -93.86 & -113.92 & -31.88 & -14.19 & 72.59 & 662.50 \\
\hline Anudem_022 & 21.60 & 37.83 & 69.03 & 88.23 & 118.54 & 5.19 & -81.90 & -98.00 & -114.46 & -31.88 & -14.19 & 73.33 & 680.86 \\
\hline Anudem_023 & 26.37 & 36.93 & 69.30 & 88.32 & 115.39 & 3.75 & -82.53 & -97.01 & -114.46 & -31.88 & -14.19 & 72.95 & 680.14 \\
\hline Anudem_024 & 26.37 & 36.93 & 69.30 & 88.32 & 115.39 & 3.75 & -82.53 & -97.01 & -114.46 & -31.88 & -14.19 & 72.95 & 680.14 \\
\hline Tin_to_Raster_007 & 39.33 & 22.53 & 72.54 & 69.15 & 85.78 & 7.98 & -58.23 & -85.85 & -107.17 & -31.88 & -14.19 & 62.51 & 594.64 \\
\hline Tin_to_Raster_008 & 42.84 & 23.88 & 71.46 & 68.97 & 85.60 & 6.81 & -60.66 & -85.40 & -107.44 & -31.88 & -14.19 & 62.80 & 599.14 \\
\hline Aster & -9.68 & 45.29 & 64.16 & 67.18 & 86.30 & 3.65 & -44.07 & -67.56 & -100.16 & -30.92 & -14.19 & 57.15 & 533.16 \\
\hline
\end{tabular}



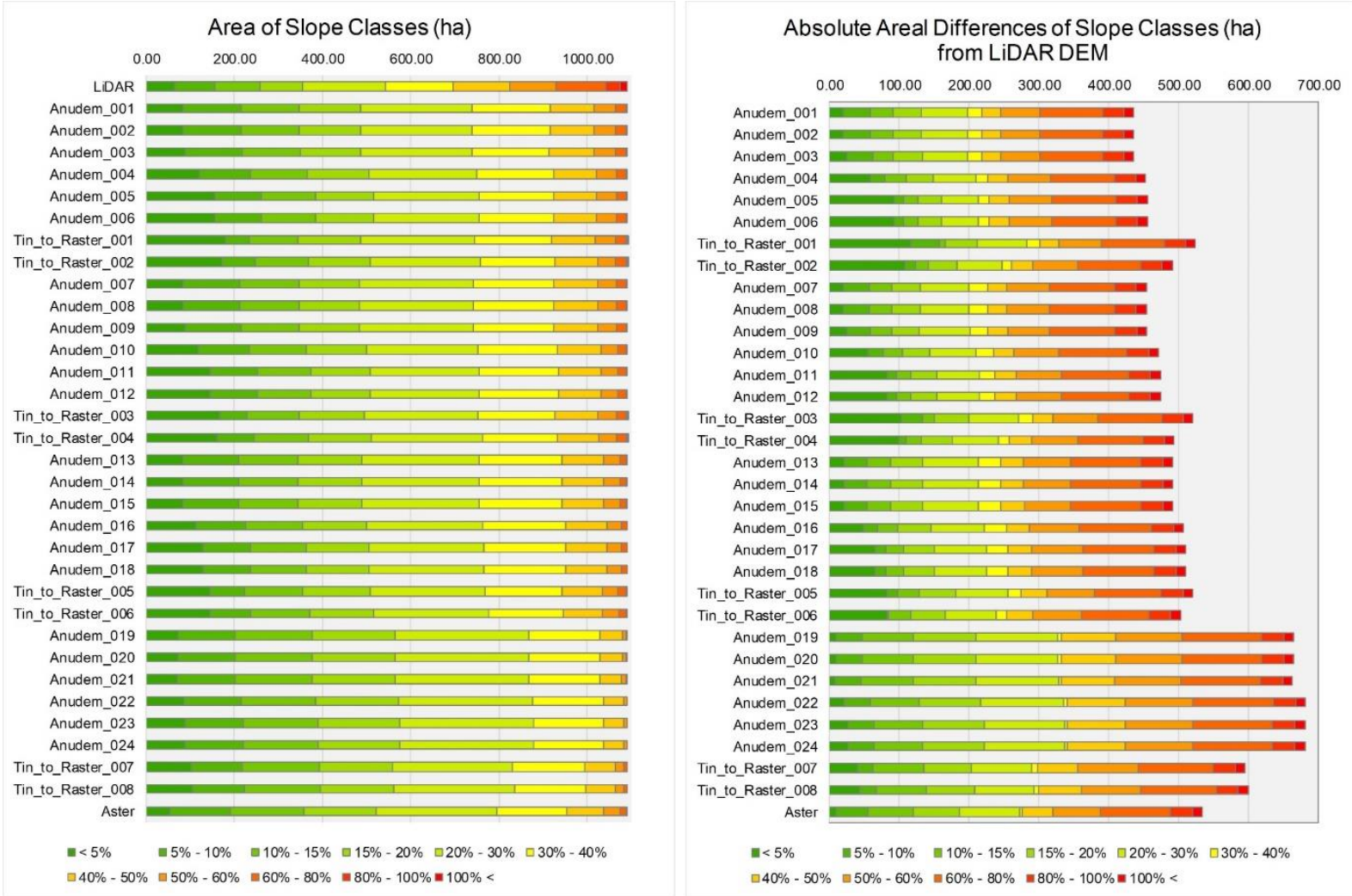

Figure 8. Area of slope classes and absolute areal differences of slope classes from LiDAR DEM.

According to the LiDAR - based DEM - derived aspect data, there was no dominant aspect class in the study area (Appendix 7-Aspect Datasets, Appendix 8-Area of Aspect Classes). However, when the results were examined closely, maximum areal differences were obtained in the northwest aspect classes (Table 7, Figure 9). According to the results of the areal differences of aspect classes the best results were obtained by the "Anudem_003" dataset. Similar to the slope difference results, Anudem_009 at 5 $\mathrm{m}$ resolution, Anudem_013-014 at $10 \mathrm{~m}$ resolution and ASTER at $30 \mathrm{~m}$ resolution had the best comparison results.

Table 7. Areal differences of aspect classes from LiDAR-based DEM.

\begin{tabular}{|c|c|c|c|c|c|c|c|c|c|c|c|}
\hline \multirow{2}{*}{ Aspect Dataset } & \multicolumn{9}{|c|}{ Areal Differences of Aspect Classes from LiDAR-based DEM (ha) } & \multirow{2}{*}{$\begin{array}{c}\text { Std. } \\
\text { Dev. } \\
\text { of } \\
\text { Diff. }\end{array}$} & \multirow{2}{*}{$\begin{array}{l}\text { Abs. } \\
\text { Total } \\
\text { Diff. }\end{array}$} \\
\hline & Flat & North & NorthEast & East & SouthEast & South & SouthWest & West & NorthWest & & \\
\hline Anudem_001 & -7.10 & 11.64 & -5.13 & -3.96 & -2.05 & 18.19 & 17.39 & -1.35 & -27.62 & 13.46 & 94.43 \\
\hline Anudem_002 & -7.10 & 11.64 & -5.13 & -3.96 & -2.05 & 18.19 & 17.39 & -1.35 & -27.62 & 13.46 & 94.43 \\
\hline Anudem_003 & -7.10 & 11.77 & -5.59 & -4.25 & -1.07 & 17.37 & 17.26 & -1.52 & -26.87 & 13.18 & 92.78 \\
\hline Anudem_004 & -7.10 & 8.11 & -0.19 & -9.14 & 0.56 & 19.29 & 19.69 & -3.47 & -27.76 & 13.92 & 95.32 \\
\hline Anudem_005 & -7.10 & 8.57 & -3.84 & -8.08 & 3.19 & 20.97 & 20.77 & -6.86 & -27.62 & 14.51 & 107.00 \\
\hline Anudem_006 & -7.10 & 8.57 & -3.84 & -8.08 & 3.19 & 20.97 & 20.77 & -6.86 & -27.62 & 14.51 & 107.00 \\
\hline Tin_to_Raster_001 & 153.77 & -9.15 & -20.20 & -26.85 & -18.86 & -9.23 & -0.06 & -34.31 & -35.12 & 55.49 & 307.55 \\
\hline Tin_to_Raster_002 & 105.65 & -5.77 & -16.09 & -23.96 & -8.41 & 1.19 & 8.77 & -28.32 & -33.05 & 39.54 & 231.20 \\
\hline Anudem_007 & -7.10 & 11.61 & -4.64 & -4.70 & -1.20 & 17.61 & 18.68 & -0.87 & -29.40 & 13.96 & 95.82 \\
\hline Anudem_008 & -7.10 & 11.61 & -4.64 & -4.70 & -1.20 & 17.61 & 18.68 & -0.87 & -29.40 & 13.96 & 95.82 \\
\hline Anudem_009 & -7.10 & 11.87 & -5.20 & -5.12 & 0.18 & 16.35 & 18.56 & -0.85 & -28.68 & 13.66 & 93.89 \\
\hline Anudem_010 & -7.10 & 8.82 & -1.93 & -7.23 & 1.81 & 19.91 & 18.63 & -4.12 & -28.79 & 14.05 & 98.34 \\
\hline Anudem_011 & -7.10 & 8.91 & -4.50 & -7.02 & 3.99 & 20.23 & 20.36 & -6.24 & -28.62 & 14.52 & 106.96 \\
\hline Anudem_012 & -7.10 & 8.91 & -4.50 & -7.02 & 3.99 & 20.23 & 20.36 & -6.24 & -28.62 & 14.52 & 106.96 \\
\hline Tin_to_Raster_003 & 127.84 & -7.28 & -17.23 & -25.02 & -12.65 & -6.94 & 5.44 & -31.32 & -32.85 & 46.69 & 266.58 \\
\hline Tin_to_Raster_004 & 87.34 & -4.50 & -13.93 & -22.46 & -4.05 & 2.57 & 12.43 & -26.40 & -31.01 & 33.64 & 204.69 \\
\hline
\end{tabular}




\begin{tabular}{c|ccccccccc|cc} 
Anudem_013 & -7.10 & 12.67 & -4.64 & -5.77 & 0.42 & 20.64 & 15.22 & -0.26 & -31.19 & 14.52 & 97.93 \\
Anudem_014 & -7.10 & 12.67 & -4.64 & -5.77 & 0.42 & 20.64 & 15.22 & -0.26 & -31.19 & 14.52 & 97.93 \\
Anudem_015 & -7.10 & 13.09 & -4.75 & -6.07 & 1.17 & 19.00 & 16.29 & -0.84 & -30.80 & 14.37 & 99.13 \\
Anudem_016 & -7.10 & 10.30 & -2.95 & -7.45 & 2.46 & 21.28 & 16.67 & -2.36 & -30.86 & 14.59 & 101.45 \\
Anudem_017 & -7.10 & 11.10 & -5.48 & -6.94 & 4.38 & 21.30 & 16.87 & -3.76 & -30.38 & 14.71 & 107.33 \\
Anudem_018 & -7.10 & 11.10 & -5.48 & -6.94 & 4.38 & 21.30 & 16.87 & -3.76 & -30.38 & 14.71 & 107.33 \\
Tin_to_Raster_005 & 90.75 & -4.38 & -12.95 & -22.23 & -4.61 & -3.27 & 13.14 & -27.00 & -29.45 & 34.51 & 207.78 \\
Tin_to_Raster_006 & 62.24 & -2.23 & -10.64 & -20.33 & 0.88 & 5.10 & 16.15 & -22.47 & -28.70 & 25.87 & 168.74 \\
Anudem_019 & -7.10 & 6.71 & 5.03 & -12.90 & 8.88 & 21.05 & 25.94 & -9.02 & -38.59 & 18.42 & 135.22 \\
Anudem_020 & -7.10 & 6.71 & 5.03 & -12.90 & 8.88 & 21.05 & 25.94 & -9.02 & -38.59 & 18.42 & 135.22 \\
Anudem_021 & -7.10 & 6.71 & 5.30 & -12.90 & 8.43 & 20.69 & 25.76 & -8.39 & -38.50 & 18.27 & 133.78 \\
Anudem_022 & -7.10 & 6.08 & 5.03 & -12.36 & 6.54 & 24.02 & 21.80 & -5.78 & -38.23 & 17.81 & 126.94 \\
Anudem_023 & -7.10 & 6.35 & 4.85 & -11.91 & 7.35 & 23.93 & 21.08 & -6.23 & -38.32 & 17.75 & 127.12 \\
Anudem_024 & -7.10 & 6.35 & 4.85 & -11.91 & 7.35 & 23.93 & 21.08 & -6.23 & -38.32 & 17.75 & 127.12 \\
Tin_to_Raster_007 & 25.84 & 0.59 & -1.00 & -22.08 & 13.56 & 4.94 & 23.78 & -16.67 & -28.96 & 18.40 & 137.43 \\
Tin_to_Raster_008 & 16.39 & 1.58 & -1.09 & -20.91 & 15.27 & 8.90 & 22.07 & -12.98 & -29.23 & 16.77 & 128.43 \\
Aster & -6.73 & 10.33 & 4.18 & -5.09 & -5.37 & 26.02 & 13.44 & -14.48 & -22.30 & 14.10 & 107.93 \\
\hline
\end{tabular}
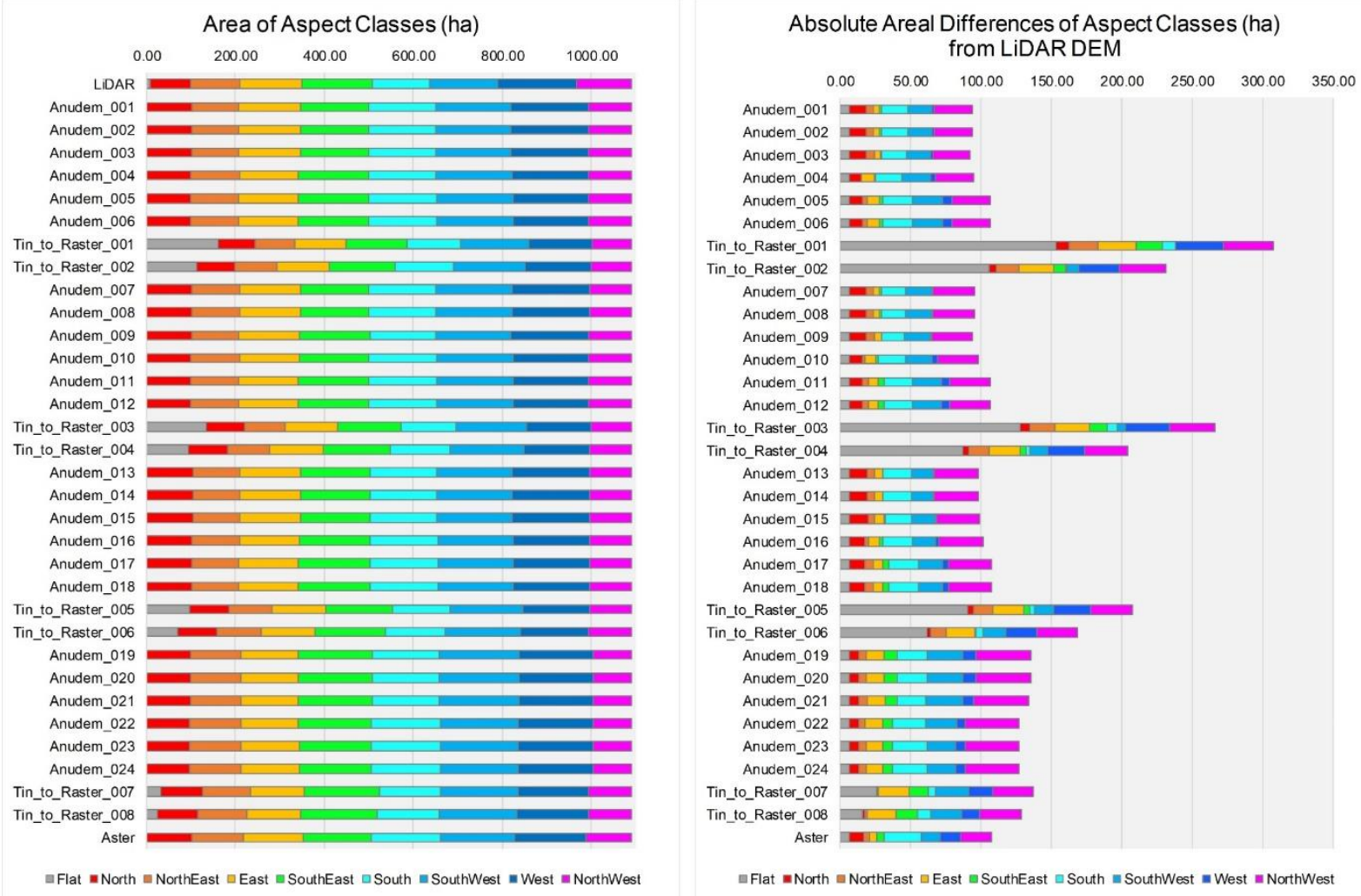

Figure 9. Area of aspect classes and absolute areal differences of aspect classes from LiDAR DEM.

According to slope and aspect differences analysis results, percentage differences were presented in Appendix 9-Absolute \% Difference for each Slope Class and Appendix 10-Absolute \% Difference for each Aspect Class for each slope and aspect classes. For all slope datasets, the maximum percentage difference was determined in the $100 \%$ < slope class and the minimum percentage difference was determined in the 30-40\% class. For all aspect datasets, the maximum percentage difference was determined in the flat class. The northwest class has the second highest percentage difference. The minimum percentage difference was determined in the southeast class.

\section{Conclusion}


Data accuracy is of paramount importance, especially if the data will be used as a basis for planning and application. In large-area studies, data acquisition costs can be considered as important as accuracy. In addition, the detail, precision and volume of the data affect the accuracy of planning as well as the time to analyze. In this context, it is very important to determine the optimals of the data to be used in the study. Generally, the error or difference from the data considered as reference, is measured with point based approaches. However, such approaches are based on sampling and statistical evaluations are made on the ability to represent the study area. Thanks to the developing technological opportunities, the variety of data sources and accordingly the variety of data continues to increase day by day. In this way, data from different sources with different features and accuracies can be accessed for any field. Thus, it is possible to compare data with different characteristics in the whole study area. Area-based assessments began to be replaced by sampling-based statistics and accuracy assessment techniques. By making such assessments, it is possible to talk about real values instead of confidence level.

Based on the areal analysis results, it is clear that, at least for this study area, for contour lines-based DEM generation, ANUDEM interpolator deliver the most reliable results. However, accuracy rates are similar at $2.5 \mathrm{~m}, 5 \mathrm{~m}$ and $10 \mathrm{~m}$ resolutions. In this context, $2.5 \mathrm{~m}$ and $5 \mathrm{~m}$ resolutions can be accepted as superfluous. It should not be forgotten that, every area on the earth has unique topography. The selection of the appropriate interpolation method and the resolution for topographic analysis depends on the precision of the data and the ability to represent the terrain. Therefore, as mentioned by Burrough (1986), "A good GIS should include a range of interpolation techniques that allow the user to choose the most appropriate method for the job at hand". In this context, according to the results of the analysis selected and applied, the following statements can be made as supported by Chang and Tsai (1991), Toutin (2002), Grohmann (2015) and Szabó et al. (2015). The accuracy of the surface model decreases in the case of steeper slopes and also, accuracy of slope and aspect decrease as a DEM resolution decreases.

\section{References}

Akima, H. (1978). A method of bivariate interpolation and smooth surface fitting for irregularly distributed data points. ACM Transactions on Mathematical Software (TOMS), 4(2), 148-159.

Aruga, K., Chung, W., Akay, A., Sessions, J., Miyata, E. S. (2007). Incorporating Soil Surface Erosion Prediction into Forest Road Alignment Optimization. International Journal of Forest Engineering, 18(1), 24-32.

Aryal, R. R., Latifi, H., Heurich, M., Hahn, M. (2017). Impact of Slope, Aspect, and Habitat-Type on LiDARDerived Digital Terrain Models in a Near Natural, Heterogeneous Temperate Forest. PFG - Journal of Photogrammetry, Remote Sensing and Geoinformation Science, 85(4), 243-255.

Aydın, A., Tecimen, H. B. (2010). Temporal soil erosion risk evaluation: a CORINE methodology application at Elmalı dam watershed, Istanbul. Environmental Earth Sciences, 61(7), 1457-1465.

Band, L. E. (1986). Topographic partition of watersheds with digital elevation models. Water Resources Research, 22(1), 15-24.

Bater, C. W., Coops, N. C. (2009). Evaluating error associated with lidar-derived DEM interpolation. Computers \& Geosciences, 35(2), 289-300.

Behrens, T., Schmidt, K., MacMillan, R. A., Viscarra Rossel, R. A. (2018). Multi-scale digital soil mapping with deep learning. Scientific Reports, 8(1), 15244. 
Behrens, T., Zhu, A. X., Schmidt, K., Scholten, T. (2010). Multi-scale digital terrain analysis and feature selection for digital soil mapping. Geoderma, 155(3), 175-185.

Bettinger, P., Boston, K., Siry, J. P., Grebner, D. L. (2010). Forest Management and Planning: Elsevier Science.

Beven, K. J., Kirkby, M. J. (1979). A physically based, variable contributing area model of basin hydrology / Un modèle à base physique de zone d'appel variable de l'hydrologie du bassin versant. Hydrological Sciences Bulletin, 24(1), 43-69.

Blöschl, G., Sivapalan, M. (1995). Scale issues in hydrological modelling: A review. Hydrological Processes, 9(34), 251-290.

Briggs, I. C. (1974). Machine contouring using minimum curvature. Geophysics, 39(1), 39-48.

Burrough, P. A. (1986). Principles of geographical information systems for land resources assessment. Oxford Oxfordshire, New York: Clarendon Press, Oxford University Press.

Chang, K.-t., Tsai, B.-w. (1991). The Effect of DEM Resolution on Slope and Aspect Mapping. Cartography and Geographic Information Systems, 18(1), 69-77.

Chen, Y., Zhou, Q. (2013). A scale-adaptive DEM for multi-scale terrain analysis. International Journal of Geographical Information Science, 27(7), 1329-1348.

De Meij, A., Bossioli, E., Penard, C., Vinuesa, J. F., Price, I. (2015). The effect of SRTM and Corine Land Cover data on calculated gas and PM10 concentrations in WRF-Chem. Atmospheric Environment, 101, 177-193.

Dong, P., Chen, Q. (2017). LiDAR Remote Sensing and Applications. Boca Raton: CRC Press.

Dragos, B., Karstenb, J. (2008). Filtering Process of LIDAR Data. XXIst ISPRS Congress. Beijing, CHINA, pp. $815-820$

Duvemo, K., Lämås, T. (2006). The influence of forest data quality on planning processes in forestry. Scandinavian Journal of Forest Research, 21(4), 327-339.

Evans, I. S. (1980). An integrated system of terrain analysis and slope mapping. Zeitschrift fur Geomorphologie, Supplementband, 36, 274-295.

Fernández-Landa, A., Fernández-Moya, J., Tomé, J. L., Algeet-Abarquero, N., Guillén-Climent, M. L., Vallejo, R., Sandoval, V., Marchamalo, M. (2018). High resolution forest inventory of pure and mixed stands at regional level combining National Forest Inventory field plots, Landsat, and low density lidar. International Journal of Remote Sensing, 39(14), 4830-4844.

Fisher, P. F., Tate, N. J. (2006). Causes and consequences of error in digital elevation models. Progress in Physical Geography, 30(4), 467-489.

Fleming, C., Giles, J. R. A., Marsh, S. H. (2010). Elevation Models for Geoscience: Geological Society. 
Flores-Prieto, E., Quénéhervé, G., Bachofer, F., Shahzad, F., Maerker, M. (2015). Morphotectonic interpretation of the Makuyuni catchment in Northern Tanzania using DEM and SAR data. Geomorphology, 248, 427-439.

Florinsky, I. (2016). Digital Terrain Analysis in Soil Science and Geology: Elsevier Science.

Fortune, S. (1987). A sweepline algorithm for Voronoi diagrams. Algorithmica, 2(1-4), 153-174.

General Directorate of Mapping (2019). Technical Characteristics of Products, 1/25000 Scale Topographical Map.

Gonga-Saholiariliva, N., Gunnell, Y., Petit, C., Mering, C. (2011). Techniques for quantifying the accuracy of gridded elevation models and for mapping uncertainty in digital terrain analysis. Progress in Physical Geography: Earth and Environment, 35(6), 739-764.

Goodbody, R. T., Coops, C. N., Hermosilla, T., Tompalski, P., Pelletier, G. (2018). Vegetation Phenology Driving Error Variation in Digital Aerial Photogrammetrically Derived Terrain Models. Remote Sensing, 10(10).

Goodchild, M. F., Mark, D. M. (1987). The fractal nature of geographic phenomena. Annals of the Association of American Geographers, 77(2), 265-278.

Grohmann, C. H. (2015). Effects of spatial resolution on slope and aspect derivation for regional-scale analysis. Computers \& Geosciences, 77, 111-117.

Hardy, R. L. (1971). Multiquadric equations of topography and other irregular surfaces. Journal of geophysical research, 76(8), 1905-1915.

Hengl, T. (2006). Finding the right pixel size. Computers \& Geosciences, 32(9), 1283-1298.

Hutchinson, M. (1989). A new procedure for gridding elevation and stream line data with automatic removal of spurious pits. Journal of Hydrology, 106(3-4), 211-232.

Hutchinson, M. (1996). A locally adaptive approach to the interpolation of digital elevation models. Proceedings, Third International Conference/Workshop on Integrating GIS and Environmental Modeling, pp. 21-26.

Hutchinson, M., Bischof, R. (1983). A new method for estimating the spatial distribution of mean seasonal and annual rainfall applied to the Hunter Valley, New South Wales. Australian Meteorological Magazine, 31(3), 179184.

Hutchinson, M. F., Xu, T., Stein, J. A. (2011). Recent progress in the ANUDEM elevation gridding procedure. Proceedings of the Geomorphometry, 19-22.

Jing, C., Shortridge, A., Lin, S., Wu, J. (2014). Comparison and validation of SRTM and ASTER GDEM for a subtropical landscape in Southeastern China. International Journal of Digital Earth, 7(12), 969-992.

Li, X., Shen, H., Feng, R., Li, J., Zhang, L. (2017). DEM generation from contours and a low-resolution DEM. ISPRS Journal of Photogrammetry and Remote Sensing, 134, 135-147.

Li, Z., Zhu, Q., Gold, C. (2005). Digital terrain modeling : principles and methodology. New York: CRC Press. 
Lidberg, W., Nilsson, M., Ågren, A. (2019). Using machine learning to generate high-resolution wet area maps for planning forest management: A study in a boreal forest landscape. Ambio.

Liu, X. (2008). Airborne LiDAR for DEM generation: some critical issues. Progress in Physical Geography, 32(1), 31-49.

Makarovic, B. (1977). Regressive rejection - a digital data compression technique. Proc. ASP/ACSM Fall Technical Meeting, Little Rock, USA.

Makarovic, B. (1984). Structures for geo-information and their application in selective sampling for digital terrain models. ITC journal(4), 285-295.

Mitas, L., Mitasova, H. (1999). Spatial interpolation. In: Longley, P., Goodchild, M. F., Maguire, D. J., Rhind, D. W., eds. Geographical information systems: principles, techniques, management and applications. New York: Wiley, pp. 481-492.

Mo, D., Fuchs, H., Fehrmann, L., Yang, H., Lu, Y., Kleinn, C. (2015). Local Parameter Estimation of Topographic Normalization for Forest Type Classification. IEEE Geoscience and Remote Sensing Letters, 12(9), 1998-2002.

Mukherjee, S., Joshi, P. K., Mukherjee, S., Ghosh, A., Garg, R. D., Mukhopadhyay, A. (2013). Evaluation of vertical accuracy of open source Digital Elevation Model (DEM). International Journal of Applied Earth Observation and Geoinformation, 21, 205-217.

Nyquist, H. (1924). Certain Factors Affecting Telegraph Speed. Transactions of the American Institute of Electrical Engineers, XLIII, 412-422.

Oky Dicky Ardiansyah, P., Yokoyama, R. (2002). DEM generation method from contour lines based on the steepest slope segment chain and a monotone interpolation function. ISPRS Journal of Photogrammetry and Remote Sensing, 57(1), 86-101.

Polat, N., Uysal, M. (2015). Investigating performance of Airborne LiDAR data filtering algorithms for DTM generation. Measurement, 63, 61-68.

Rather, M. A., Farooq, M., Meraj, G., Dada, M. A., Sheikh, B. A., Wani, I. A. (2018). Remote Sensing and GIS Based Forest Fire Vulnerability Assessment in Dachigam National Park, North Western Himalaya. Asian Journal of Applied Sciences, 11, 98-114.

Rexer, M., Hirt, C. (2014). Comparison of free high resolution digital elevation data sets (ASTER GDEM2, SRTM v2.1/v4.1) and validation against accurate heights from the Australian National Gravity Database. Australian Journal of Earth Sciences, 61(2), 213-226.

Robinson, A. H., Morrison, J. L., Muehrcke, P. C., Kimerling, A. J., Guptill, S. C. (2009). Elements of Cartography: Wiley India Pvt. Limited.

Shannon, C. E. (1934). Communication in the presence of noise. Proc. Inst. Radio Eng, 371.

Szabó, G., Singh, S. K., Szabó, S. (2015). Slope angle and aspect as influencing factors on the accuracy of the SRTM and the ASTER GDEM databases. Physics and Chemistry of the Earth, Parts A/B/C, 83-84, 137-145. 
Tachikawa, T., Kaku, M., Iwasaki, A., Gesch, D. B., Oimoen, M. J., Zhang, Z., Danielson, J. J., Krieger, T., Curtis, B., Haase, J., Abrams, M., Carabajal, C. (2011). ASTER Global Digital Elevation Model Version 2 - summary of validation results. p. 27.

Talhofer, V., Kovarik, V., Rybansky, M., Hofmann, A., Hubacek, M., Hoskova-Mayerova, S. (2015). Terrain Analysis for Armed Forces. In: Brus, J., Vondrakova, A., Vozenilek, V., eds. Modern Trends in Cartography: Selected Papers of CARTOCON 2014. Cham: Springer International Publishing, pp. 519-532.

Tarboton, D. G. (2003). Terrain analysis using digital elevation models in hydrology. 23rd ESRI international users conference. San Diego, California.

Tarolli, P., Cavalli, M., Masin, R. (2019). High-resolution morphologic characterization of conservation agriculture. Catena, 172, 846-856.

Toutin, T. (2002). Impact of terrain slope and aspect on radargrammetric DEM accuracy. ISPRS Journal of Photogrammetry and Remote Sensing, 57(3), 228-240.

Watson, D. F. (1992). Contouring: A Guide to the Analysis and Display of Spatial Data: Pergamon Press.

Wilson, J. P., Gallant, J. C. (2000). Terrain analysis : principles and applications. New York: Wiley.

Wong, W. V. C., Tsuyuki, S., Loki, K., Phua, M. H. (2014). Accuracy assessment of global topographic data (SRTM \& ASTER GDEM) in comparison with lidar for tropical montane forest. Proceedings of the 35th Asian Conference on Remote Sensing. Nay Pyi Taw, Myanmar, pp. 27-31.

Yurtseven, H. (2019). Comparison of GNSS-, TLS- and Different Altitude UAV-Generated Datasets on The Basis of Spatial Differences. ISPRS International Journal of Geo-Information, 8(4).

Yurtseven, H., Akgul, M., Coban, S., Gulci, S. (2019). Determination and accuracy analysis of individual tree crown parameters using UAV based imagery and OBIA techniques. Measurement, 145, 651-664.

Zhang, X., Drake, N. A., Wainwright, J., Mulligan, M. (1999). Comparison of slope estimates from low resolution DEMs: scaling issues and a fractal method for their solution. Earth Surface Processes and Landforms, 24(9), 763779. 